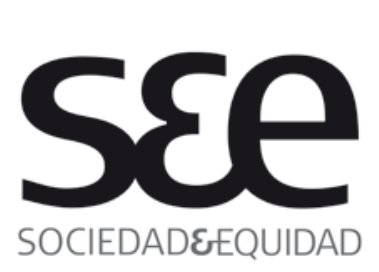

\title{
Cambio y Transculturalidad La construcción de la identidad cultural kichwa en Colombia
}

\author{
Cultural change and Transculturality \\ The construction of kichwa cultural identity in \\ Colombia
}

$\begin{array}{ll}\text { Nombre: } & \text { Vivian Martínez Díaz } \\ \text { Filiación: } & \text { Universidad de los Andes } \\ \text { País: } & \text { Colombia } \\ \text { Correo: } & \text { va.martinez61@uniandes.edu.co }\end{array}$

\section{Resumen}

Los kichwas $u$ otavalos son un pueblo indígena andino ligado histórica y culturalmente a la ciudad de Otavalo en el norte del Ecuador. Estos incorporan las prácticas de la migración, el comercio y la interpretación musical como estilo de vida, pero también como parte de su identidad cultural. Desde la práctica cotidiana de la migración trasnacional, los kichwas se han definido como sujetos indígenas a la luz del cambio y la movilidad. Desde 1940, tuvo lugar un éxodo de kichwas a Colombia. Algunas familias pertenecientes a este grupo étnico migraron al país con el fin de realizar intercambios comerciales. Con el tiempo, los kichwas se conformaron como colonia en Bogotá y más tarde, se organizaron políticamente como cabildo indígena. A través de la acción del cabildo, se han fundado historias oficiales donde la migración y el comercio, sumadas a cualidades como el prestigio, la solidaridad y el compañerismo, se legitiman como elementos simbólicos de la identidad cultural de los kichwas en Bogotá. Esto es posible a través de la representación de narrativas de próceres y pioneros de la migración y el asentamiento que hacen parte de la historia colectiva kichwa.

\section{Palabras Claves}

Kichwas, migración, comercio, prestigio, solidaridad, compañerismo, identidad cultural.

\footnotetext{
${ }^{1}$ La autora es Maestra en Antropología y estudiante de Doctorado en Antropología. Sus líneas de investigación son: Estudios culturales, antropología del género, antropología política y estudios feministas.
} 


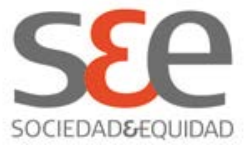

\begin{abstract}
The Kichwas or Otavalos are an indigenous people culturally and historically linked to the city of Otavalo in Ecuador. These people incorporate practices of migration, trade and musical interpretation as a way of living, but also as a part of their cultural identity. The Kichwas have been defined as indigenous subjects in dynamics of cultural change. Indeed, this cultural change is due to daily practice of transnational migration. Since 1940, many Kichwas have migrated to Colombia in order to make commercial exchanges. Afterwards, the Kichwas have organized themselves as a colony in Bogotá, and later as an indigenous government institution named 'Cabildo Indígena'. Across the political action of the Cabildo, an official history of migration and settlement of these indigenous people in Colombia was constructed. In this history, migration, trade, music, prestige, solidarity and companionship are legitimized as symbolic elements of Kichwa cultural identity. This legitimation is possible through narratives of 'próceres' and 'pioneros' that represent the settlement of the Kichwas in the city.
\end{abstract}

\title{
Keywords
}

Kichwas, migration, trade, prestige, solidarity, companionship, cultural identity.

\begin{abstract}
$* * *$

\section{Introducción}

Los kichwas u otavalos, son un pueblo indígena andino originario de la ciudad de Otavalo al norte del Ecuador. Estos han adoptado las prácticas de la migración, el comercio y la música como estilo de vida, y las han incorporado como elementos constitutivos de su identidad cultural. Hoy se puede hablar de la configuración de colonias y diásporas kichwas en los países del mundo. Por esta razón, los kichwas reflejan cómo el sujeto indígena que se construía en las nociones de lo "auténtico" y lo "prístino", se convierte en uno cosmopolita que sortea la movilidad y el cambio cultural sin dejar de lado una conciencia étnica fuerte tanto individual como colectiva.
\end{abstract}

Desde 1940, algunas familias kichwas migraron a Colombia con el fin de realizar intercambios comerciales en el país. Transcurridas unas décadas, los kichwas se conformaron como colonia en la ciudad de Bogotá y se organizaron políticamente en torno a la institución del cabildo indígena en el año 2006. 


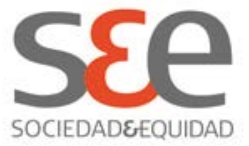

Dicha institución surgió como resultado de la jurisdicción especial que consagra derechos diferenciales a los pueblos indígenas en el marco de la política multicultural del Estado colombiano. Si bien, el cabildo indígena es una organización político-cultural impuesta por España en la época colonial con el objetivo de establecer formas de gobierno y deliberación para los "salvajes" que se encaminaban a la vida civilizada, este se ha reinventado gracias al reconocimiento de la diversidad cultural consagrado en la Constitución Política de 1991. Así, la fundación de los cabildos tuvo como pretensión el establecer puentes de diálogo entre el Estado colombiano y los pueblos indígenas.

Al iniciar el cabildo sus actividades políticas, un grupo de líderes del pueblo kichwa construyó una historia oficial de la migración y el asentamiento de este en Bogotá. En dicha historia se definieron las prácticas de la migración y el comercio como parte de la identidad cultural kichwa, sumadas a cualidades como la habilidad en la fabricación de textiles, la solidaridad y el compañerismo entre miembros de la colonia kichwa a través de la música y el deporte. Este proceso ha tenido lugar en medio de las vicisitudes del cambio y la movilidad que han caracterizado al pueblo kichwa. El afrontar el cambio y la movilidad para estos ha traído consigo una tensión por mantener prácticas e identidades culturales esencializadas en la ciudad. De este modo, la migración, el comercio, la solidaridad y el prestigio del pueblo kichwa han sido funcionales a la permanencia y continuidad de la colectividad en el tiempo. Esto se manifiesta en las voluntades de los líderes que construyeron esta historia y en la narrativa de próceres y pioneros que representan con sus historias los elementos simbólicos que definen esta identidad.

El propósito de este artículo es interpretar la historia oficial de la migración y el asentamiento del pueblo kichwa en Colombia producida por los líderes del Cabildo Mayor Kichwa Camainkibo de Bogotá. Dicha interpretación tomará como referente la crítica a la representación y la autoridad en la antropología, así como algunos aportes de la disciplina a la investigación sobre indigeneidades. Esto remite al análisis textual de las culturas, a saber, el examen de relatos e historias de los kichwas en Colombia. Como es de suponer, la historia de la migración y el asentamiento refleja los valores y pensamientos de la cultura kichwa. De igual modo, dicha historia muestra los deseos y las intenciones de los líderes del cabildo con la creación de esta. En este mismo sentido, la historia oficial cumple un papel fundamental en la reproducción y mantenimiento de la colectividad kichwa en el tiempo.

El presente texto se dividirá en cuatro partes. En primer lugar, se expondrán algunos antecedentes históricos relacionados con la construcción de la identidad cultural del pueblo kichwa u otavalo. En segundo lugar, se presentarán algunas reflexiones sobre cómo los kichwas subvierten el legado 


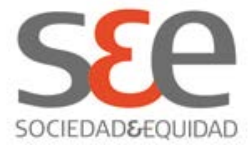

etnoarqueológico del indio para convertirse en indígenas cosmopolitas que afrontan el cambio y la movilidad cultural, y que refutan las nociones tradicionales de la cultura. En tercer lugar, se expondrán los lineamientos metodológicos que guiaron este análisis de la historia oficial. En cuarto lugar, se interpretará la historia oficial de la migración y el asentamiento de los kichwas en Colombia ya previamente mencionada. Finalmente, se esbozarán las conclusiones sobre este trabajo.

\section{El devenir de los otavalos}

La ciudad de San Luis de Otavalo está ubicada a cien metros de la frontera con Colombia y a ciento cincuenta de la ciudad de Quito, en medio de los volcanes Cotacachi e Imbabura. Esta ciudad es conocida por la prosperidad derivada de sus actividades económicas de subsistencia tales como la agricultura, el turismo, el comercio, la manufactura de textiles y la música. Estas últimas tres actividades han tenido un gran impacto internacional, puesto que los kichwas han adoptado la migración como una forma de obtener ingresos y, más aún, como un estilo de vida enraizado en los medios urbanos. Es así como los kichwas en el proceso de la migración y el asentamiento, llegan a reproducir tales prácticas. Adicionalmente, Otavalo se ha construido como un espacio local en el que confluyen diversas diferencias étnico-raciales entre indígenas y mestizos, y como un campo de movilizaciones políticas y puesta en marcha de aparatos de justicia indígena locales.

Algunos especialistas en temas relacionados con los pueblos indígenas andinos (Colloredo-Mansfeld, 1998, 2002; Korovkin, 1998; Maldonado, 2002; Meisch, 2002; Wibbelsman, 2005), argumentan que uno de los posibles orígenes del pueblo kichwa u otavalo se encuentra en un grupo élite de migrantes y comerciantes especializados en el intercambio de mercancías conocidos como "mindalaes". Michelle Wibbelsman (2005) y Gina Maldonado (2002) sostienen que los mindalaes gozaron de privilegios económicos bajo la gobernanza de los incas en el siglo XVI y los designios de la corona española en los siglos posteriores. Sin embargo, Lynn A. Meisch (2002) argumenta que los mindalaes sí estuvieron sujetos a sistemas de explotación económica masiva como la mita, la encomienda y el wasipungu. De este modo, la tradición mindalá se convierte en un referente de prestigio e identificación del pueblo kichwa.

También se habla de una ascendencia inca en los otavalos. En la convivencia con los incas durante los siglos XV y XVI, los otavalos adoptaron la lengua y el vestido tradicional de las mujeres. En primer lugar, la lengua quichua fue aprendida por los indígenas otavalos con el fin de afianzar intercambios comerciales. Esta fue una de las influencias más trascendentales de los incas sobre los otavalos (Meisch, 2002). En segundo lugar, el traje femenino conformado por faldas largas de color oscuro llamadas Anakus 0 


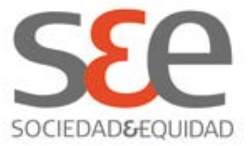

Anacos, las blusas tejidas y el uso de pañoletas llamadas Fachalinas, fue adoptado por las mujeres otavalos. De ahí que los otavalos atribuyan sus orígenes no sólo al pasado como mindalaes y mercaderes migrantes, sino también a los Incas. Esto se evidencia en la configuración de movimientos sociales de indígenas otavalos, en la promoción de mercancías y en la celebración de festividades como el Inti Raymi, la cual también se conoce como fiesta de San Juan. Llegado a este punto, se puede afirmar que la retórica del origen inca permanece en el turismo que actualmente está en auge en la ciudad de Otavalo. Empero, si bien se habla de una ascendencia inca en los otavalos, es necesario aclarar que estos como pueblo indígena son también descendientes de diversos grupos étnicos como los Cochasquís y los Caranqui, de quienes también adoptaron igualmente la práctica de la migración por fuera del territorio (Meisch, 2002).

La explotación de trabajo humano durante la colonia española en el Ecuador, también influyó en la construcción cultural del pueblo Otavalo. Con la llegada de los españoles a la región andina en 1532, las encomiendas fueron delimitadas por los conquistadores en el norte de ese país. De este modo, las encomiendas implicaron para los otavalos trabajo forzado para la producción masiva de textiles y ropas que serían vendidas posteriormente en el mercado extranjero. Al evidenciarse la rentabilidad de estas mercancías, los españoles inventaron una forma de producción y trabajo masivo denominada obraje.

Los obrajes fueron molinos construidos bajo la inspiración de los talleres textiles que proporcionaban ropas a las cortes imperiales incas y después a los españoles (Korovkin, 1998) Dicho talleres fueron reproducidos en gran escala en el norte de Ecuador en los siglos XVI y XVII. En ese entonces, los españoles introdujeron la lana de oveja, el telar de pedal y el uso de algodón tradicional del Valle de Otavalo a los obrajes (Korovkin, 1998). Fue así que con los obrajes se dio paso a una forma de producción de ropas y textiles en masa que tendría gran auge en las ciudades de Otavalo y Peguche. Más tarde, los textiles producidos en los obrajes fueron vendidos en los conocidos centros coloniales de Perú y Colombia. Con el tiempo, los obrajes fueron retomados también por algunos propietarios privados al abolirse el régimen político y económico colonial, lo cual marcó el cese paulatino de los obrajes. Esto último también se atribuyó a la proliferación de epidemias, al auge de la minería de la plata y a la implementación de políticas proteccionistas que buscaban resguardar el mercado textil de fabricaciones internacionales más económicas y competitivas (Korovkin, 1998 y Meisch, 2002). Para los últimos años del siglo XIX, los obrajes habían desaparecido completamente (Korovkin, 1998).

Durante la primera mitad del siglo XX, los otavalos eran vistos como modelos de indígenas, y como símbolos de progreso y civilización. Esta 


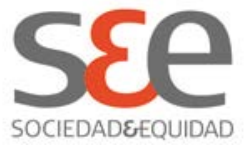

representación del indígena otavalo era reproducida por los líderes políticos de ideología liberal-nacionalista para una audiencia euro-americana en el contexto del laissez faire de la época (Maldonado, 2002: 46 y Meisch, 2002: 30). Así pues, fueron construidas diferentes representaciones simbólicas de los otavalos como "inteligentes", "limpios", "líderes", "industriales" y "prestigiosos". De esta forma, los otavalos se ubicaron en un estrato social más alto con respecto a otros grupos indígenas que eran asociados a cualidades como lo "sucio", Io "salvaje" y lo "atrasado". (Colloredo-Mansfeld, 1002). En este contexto, los indígenas otavalos se delimitaron como un grupo étnico distinto con raíces históricas y culturales en la ciudad de Otavalo, con un vestido particular, y con unas prácticas económicas de comercio y manufactura que rompían con la tenencia tradicional de la tierra por parte de los grupos indígenas (Meisch, 2002: 20-32).

A pesar de la desaparición de los obrajes y del cambio político y económico que trajo la abolición del régimen colonial, la producción de textiles y mercancías de los otavalos no cesó. Más bien, algunos trabajadores textiles otavalos tomaron los telares de pedal y tejieron diversos tipos de confecciones entre los cuales cabe destacar la imitación de casimires o paños ingleses (Korovkin, 1988, 123-124). Estos paños fueron vendidos en los mercados de Tulcán en la provincia ecuatoriana de Carchi, y en las ciudades colombianas de Pasto, Popayán y Bogotá (Meisch, 2002: 33). Para la década de los cuarenta, los otavalos empezaron a trabajar en el comercio textil y en la manufactura de artesanías en tierra colombiana. Con esto, se dio inicio a una ola migratoria de indígenas otavalos hacia Colombia, cuyo fin sería establecer intercambios comerciales en el país.

En los años sesenta y setenta, se configuró una colonia de otavalos que hacía intercambios comerciales y culturales al interior de Colombia y que compartían la ciudad de Otavalo como referente cultural (Meisch, 2002: 36). Los miembros de dicha colonia eran habitantes del occidente y centro de Bogotá que tenían negocios comerciales propios, y que estaban integrados por actividades como la música y el deporte.

Para los años ochenta, Meisch (2002) afirma que hubo un auge de la música otavaleña no sólo en la ciudad de Otavalo, sino también en los Estados Unidos y en algunos países latinoamericanos. Este auge influyó en las expresiones musicales de los indígenas otavalos en Colombia durante ese periodo. Debido a esto, diferentes grupos de música procedentes de Ecuador migraron hacia Colombia con el cometido de exponer sus producciones artísticas y establecer amistades con los miembros de la colonia otavalo bogotana. Entonces, Colombia se proyectó como un punto de confluencia de diferentes otavalos que compartían un referente cultural colectivo. 


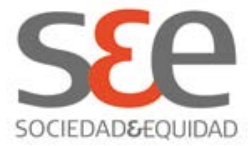

Hacia finales de los años noventa, algunos grupos musicales de la colonia otavalo bogotana emprendieron iniciativas para organizar políticamente a su comunidad. La política del multiculturalismo y del reconocimiento incorporada en la Constitución Política de 1991 trajo consigo un fenómeno de transición política donde el enfoque cultural se convirtió en un eje transversal de las instituciones, la administración y la política pública. Dicho fenómeno, tuvo como antecedente las luchas políticas de los pueblos indígenas colombianos por la autonomía y la autodeterminación. Esto se materializó en la creación de una jurisdicción especial indígena que tuvo como objetivo otorgar derechos diferenciales a los pueblos originarios en lo que atañe a la potestad de gobernarse de forma autónoma y participar políticamente. Por consiguiente, las luchas indígenas por el reconocimiento de la diversidad cultural en Colombia cimentaron la voluntad política de algunos líderes otavalos que planteaban sus propias reivindicaciones a través de la música.

Como producto de las reivindicaciones de estos líderes otavalos, surgió en el año 2006 el Cabildo Mayor Kichwa Camainkibo de Bogotá. Algunas de las intenciones de estos exponentes políticos para promover el reconocimiento de los otavalos como pueblo indígena colombiano ante el Estado, se relacionaron con la defensa de los derechos fundamentales a la salud, la educación, la participación política y la no discriminación. Para este tiempo, el cabildo se configuró como una institución de gobierno indígena con unas funciones específicas relacionadas con la asistencia social y económica a la comunidad otavalo de Bogotá. Dicha asistencia se desarrolló a través de programas de salud tradicional y seguridad alimentaria. En otro orden de ideas, el cabildo tuvo como propósito el construir identidad cultural otavalo en Bogotá por medio de la salvaguarda de prácticas consideradas como "tradicionales" y "ancestrales" tales como la migración y las habilidades en el comercio. Aparte de esto, algunas cualidades como el "prestigio", la "solidaridad" y el "compañerismo" fueron promovidas por el cabildo como formas de exaltación de la identidad cultural otavalo. Esto se refleja en la construcción de una historia oficial de la migración y el asentamiento de este pueblo indígena en Bogotá producida y promovida por algunos líderes del cabildo indígena. De ahí, los indígenas otavalos ya no se identificarían más como "otavalos" sino como "kichwas".

\section{Los kichwas y la subversión del estereotipo del sujeto indígena: identidades transculturales/identidades esencializadas}

Los antropólogos sociales han planteado diversas preguntas en torno a la construcción, negociación y articulación simbólica de las identidades étnicoraciales. Así, han surgido discusiones sobre cómo las relaciones de poder median estos procesos identitarios. En consecuencia, lo cultural se torna 


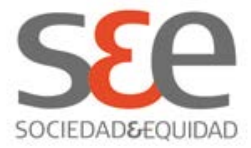

"político" y es en este escenario donde toma relevancia el discurso de la etnicidad como base de identificaciones políticas. En el escenario de lo móvil y lo cambiante ha sido indispensable concebir cómo surgen nuevas identidades y experiencias indígenas situadas en un mundo globalizado y transnacional. Esto implica reflexionar sobre la emergencia de nuevas indigeneidades contemporáneas.

El análisis clásico de la cultura se había centrado en sistematizar las concepciones y definiciones de la identidad indígena, los discursos de la indigeneidad y las experiencias de los pueblos originarios a partir de modelos analíticos reducidos y esencialistas (Jackson y Warren, 2005 y Maldonado, 2002). J ean Jackson y Key Warren (2005) entienden el esencialismo como el proceso por el cual se congela analíticamente una identidad cultural, invisiblizando los procesos históricos en los cuales se construye y se desenvuelve. Por esta razón, es necesario entender lo indígena desde marcos analíticos flexibles que comprendan las dinámicas de cambio y movilidad que configuran diferencialmente cada cultura. Esto refuta la equiparación de lo indígena con cualidades como lo "ancestral", Io "prístino" y lo auténtico, las cuales denotan un claro esencialismo.

El paso de un indio prístino, auténtico y ancestral a un indígena cosmopolita que sortea con las dinámicas de un mundo trasnacional y globalizado se refleja en los kichwas. Al incorporar las prácticas de la migración trasnacional y al poner en marcha estrategias de movilidad cultural, los kichwas subvierten el legado etnoarqueológico del indio representado como "sucio", "salvaje" e "inferior" para convertirse en indígenas universales que "se saben de todas partes y parte de todo" (Maldonado, 2002: 48). Con relación a esto, es posible analizar cómo el constructo de la identidad cultural kichwa revierte las nociones clásicas de la cultura. Frente a esto, el concepto de transculturalidad se presenta como clave para el entendimiento de las dinámicas móviles, cambiantes y performativas que definen esta identidad.

El concepto de transculturalidad, surge de la crítica a la noción tradicional de cultura. Desde esta perspectiva las culturas son entendidas como unidades homogéneas y aisladas que simbolizan las costumbres, pensamientos y prácticas de un pueblo (Welsch, 1999). Es así como la noción de cultura se caracteriza por ser una separatista, homogeneizadora y unificadora (Welsch, 1999). En su lugar, la transculturalidad plantea que en el mundo contemporáneo ya no es posible concebir las culturas bajo ese concepto puesto que cada cultura es construida a través de procesos de diferenciación, coexistencia y cooperación en el marco de la globalización y la migración transnacional (Welsch, 1999). 


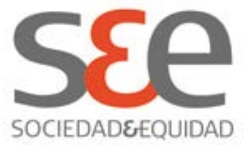

Teniendo en mente el concepto de transculturalidad, es posible afirmar que los kichwas han incluido estrategias de movilidad cultural que les han permitido refutar las nociones clásicas de la cultura. Empero, es necesario contemplar cómo el hecho de afrontar el cambio cultural a través de la puesta en marcha de dichas estrategias, cumple un rol fundamental en la reproducción de la cultura y la colectividad kichwa en el tiempo. En el escenario de la transculturalidad, los kichwas han atravesado fronteras aprendiendo prácticas, reteniendo y ejerciendo otras, sin detenerse en la homogeneización, la unificación y el separatismo. Por el contrario, en el ámbito de la migración trasnacional, los kichwas atraviesan culturas y salen libremente de estas, tomando "lo que quiero y lo que me gusta mientras pueda seguir siendo indígena en este tiempo" (Maldonado, 2002). En este sentido, se genera una especie de resiliencia cultural que consiste en la producción de respuestas adaptativas a un mundo globalizado y transnacional.

Mantener y reproducir la identidad kichwa en el tiempo es posible únicamente a través de las estrategias de movilidad cultural ya mencionadas. Estas estrategias pueden denominarse como "permanencias". A su vez, las permanencias son aquellos elementos que constituyen la identidad kichwa y que se reproducen gracias a la acción de las instituciones de gobierno indígena, y de las historias y relatos de la comunidad. Tales permanencias se reflejan en la reproducción contemporánea de prácticas y tradiciones relacionadas con la migración, el comercio, la comunicación a través de la lengua quichua, el vestido, la apropiación del ambiente y el entorno urbano, y la celebración de fiestas colectivas. Por ende, las permanencias permiten crear modelos de kichwas cuyo fin es garantizar la permanencia de la comunidad en el tiempo.

\section{Antropología, alteridad y representación: consideraciones metodológicas sobre el abordaje de la indigeneidad kichwa}

La antropología ha construido su objeto de estudio tomando como referente la alteridad, es decir, el encuentro cultural con el "otro" y el deseo de aproximarse a lo "ajeno". Esto ha implicado para muchos antropólogos el indagar en el carácter diverso de las sociedades. Paralelamente, la indagación antropológica se ha dirigido a la búsqueda de lo auténtico, y luego, al análisis de la diferencia cultural entre hombres y mujeres en una sociedad. Así, la antropología no solo se define como una ciencia de las diversidades culturales, sino como un campo de estudio sobre los seres humanos y su entorno.

En los años ochenta, la antropología tuvo que afrontar la crisis de representación de las ciencias sociales. Esta crisis radicó en una serie de acusaciones a la disciplina siempre situadas en un contexto político y económico particular. Eventos claves de este contexto fueron el periodo posterior a la Segunda Guerra Mundial, la decadencia del sistema colonial, la 


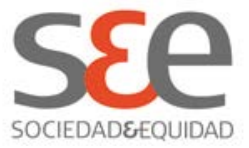

emergencia de nuevos Estados-nación, y el desarrollo de un sistema capitalista transnacional. Las acusaciones se relacionaban con el carácter androcentrista y eurocentrista de la antropología. Gran parte del objeto y método de la disciplina estuvieron marcados por el colonialismo que era inmanente al pensamiento moderno occidental y al discurso científico. Diversos antropólogos legitimaron ese orden colonial a través de sus investigaciones. En ese sentido, la crítica planteó cómo la antropología validó la desigualdad y la opresión de los países colonizados.

Empero, la antropología retomó su misma crisis para reinventarse y transformar tanto su objeto de estudio como su método. Entonces, propuso al menos tres alternativas para superar esta crítica. En primer lugar, se valorizó la importancia de los encuentros culturales con el otro y se planteó la necesidad de establecer relaciones horizontales entre los investigadores y los suj etos que aportan a la investigación. En segundo lugar, se criticó el método científico por promover el imperialismo europeo y el colonialismo. En este sentido, la antropología se alineó a la teoría social posmoderna, una que criticó cómo el discurso científico se sobreponía a otros. A su vez, esto implicó traer a colación el giro lingüístico de las ciencias sociales gracias al cual se exaltaron algunos formatos de escritura no científicos con el fin de posicionar esta misma crítica. En tercer lugar, con base a este giro lingüístico la antropología planteó nuevas formas de entender la cultura. De esta manera, la antropología posmoderna promovió la definición de las culturas como texto, lo cual condujo al entendimiento de la etnografía como texto literario.

En este orden de ideas, la antropología propuso un análisis de la cultura sustentado en lo particular. En la oposición al discurso científico de la neutralidad, la antropología apostó por la particularidad de los valores, las prácticas y los individuos que definen una cultura. Entonces, la etnografía debía dar cuenta de la vida cotidiana de los seres humanos, sus acciones, pensamientos, contradicciones y sentimientos. De igual modo, el análisis discursivo y textual de las culturas debía tomar como referente lo particular. Por ende, los métodos discursivos y literarios tales como las historias de vida y las narrativas fueron centrales en la antropología.

La investigación antropológica sobre los pueblos indígenas retoma la denuncia al carácter imperialista y colonialista de la ciencia. Para Linda Tuhiwai-Smith (2012) las formas en las que la investigación científica oprime aún están en la memoria de los países colonizados, razón por cual los pueblos originarios asumen esta como "ofensiva". La ofensa radica en dos cuestiones. En primer lugar, está el carácter de invalidez de los conocimientos de los pueblos indígenas y sus reivindicaciones ante las ciencias sociales positivistas, y en segundo lugar, está la apropiación ilegítima de los conocimientos de los 


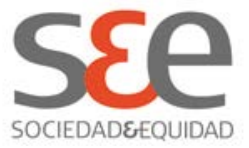

pueblos originarios por parte de los científicos sociales, unos que se autoimponen el rol de traductores de la cultura. Esto alude a la definición de un concepto de autoridad antropológica sustentado en el discurso colonial de la apropiación.

El análisis de la historia oficial de la migración y el asentamiento kichwa que analizo en este artículo, retoma tanto la crítica a la antropología como sus alternativas a la crisis de representación. De esta misma forma, asumo el carácter colonialista de la disciplina y planteo formas de hacerle frente. De cara a este cometido, trazo la necesidad de analizar las narrativas de los pueblos originarios sobre su propio origen y la posible emergencia de contranarrativas (counter-narratives) que contribuyen a superar la desigualdad y la opresión. En este mismo horizonte, para el análisis antropológico de dicha historia, retomaré las implicaciones éticas y políticas de esta lectura para la institución del cabildo.

Este análisis hace parte de una investigación más amplia sobre las mujeres indígenas que integran del cabildo kichwa y que se postulan como lideresas de esa organización. La investigación titulada "Género, etnicidad y acción colectiva: conversaciones con las mujeres indígenas del Cabildo Mayor Kichwa Camainkibo de Bogotá" puso sobre la mesa un debate sobre la escritura antropológica, la representación y la autoridad feminista. En esta investigación, develé las concepciones de la subordinación femenina y la diferencia cultural tanto el cabildo como en la colectividad kichwa poniendo en escena conversaciones sostenidas con estas mujeres. Así, la puesta en escena de estas conversaciones se reflejó en todo el texto etnográfico. No es el objeto de este artículo retomar esta investigación antropológica de manera amplia. Más bien, la mención a dicha investigación obedece a mi intención de ilustrar la procedencia y los antecedentes de este análisis antropológico de la historia oficial de la migración y el asentamiento del pueblo kichwa.

Como paso previo al trabajo etnográfico con las mujeres kichwas, para mí fue de suma importancia conocer las prácticas, pensamientos y valores del pueblo kichwa. Esto me condujo a analizar sus historias, saberes y narrativas teniendo en mente que estas representan su misma cultura. En ese sentido, la cultura kichwa se refleja en esta historia de la migración y el asentamiento en Bogotá. Con este fin, asumí que las historias indígenas incorporan conocimientos situados en relaciones sociales específicas. Las historias nunca están descontextualizadas y desvinculadas de la figura del autor. Entonces, de forma general, considero que esta historia tiene como cometido el asegurar la vinculación de la colectividad kichwa al mundo y su continuidad como pueblo indígena de generación en generación. Como lo afirma Margaret Kovach (2012), la especificidad cultural de las historias indígenas se manifiesta en enseñanzas 


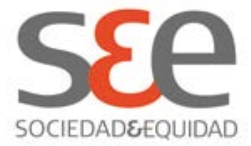

y narrativas que tienen profundas implicaciones en la investigación. Esto se relaciona con la representación errada de la especificidad cultural así como la interpretación inadecuada de la misma (Kovach, 2012: 95-96).

Finalmente, expondré algunas consideraciones sobre el abordaje que haré de la historia oficial de la migración y el asentamiento del pueblo kichwa en Bogotá. En primer lugar, asumiré que en la realización de esta historia y su interpretación cultural residen dos tipos de autoridad: por una parte, mi propia autoridad que está sustentada en mi voluntad de visibilizar las voces y posiciones particulares de los creadores de esta historia, y por otro lado, la autoridad que adquieren los escritores de esta historia y sus intereses particulares en esta. Así, estableceré una diferencia entre mi perspectiva y los puntos de vista de dichos realizadores. En segundo lugar, asumiré que la historia de la migración y el asentamiento del pueblo kichwa refleja los valores, prácticas, identidades y sujetos de definen su cultura. Entonces, puede decirse que esta historia está inmersa en un proceso de socialización que tiene como cometido la reproducción de la colectividad en el tiempo. Finalmente, consideraré que al estar las historias imbricadas en relaciones de poder, es imposible mitigar las consecuencias sociales y políticas tanto de la historia oficial como de su interpretación cultural. Por lo tanto, sostengo que lo ideal no es erradicar la tensión, sino contemplarla dentro de un imperativo ético de no dañar al otro.

\section{La historia oficial de los kichwas en Colombia: la construcción de la identidad cultural indígena mediada por el cabildo kichwa}

Al conformarse el cabildo kichwa en el año 2006, algunos de sus líderes políticos iniciaron un proceso de reconstrucción de la historia de la migración y el asentamiento de los kichwas en Colombia. Dicha reconstrucción fue posible en el marco de una iniciativa de fortalecimiento de la medicina tradicional kichwa dirigida por éste. De esta iniciativa, surgió un documento titulado "Cartilla de Fortalecimiento de la Medicina Tradicional de la Comunidad Kichwa de Bogotá". Si bien, el documento fue producido por un equipo de investigación liderado por estos exponentes políticos, lo cierto es que la "Comunidad Indígena Kichwa de Bogotá" aparece como su único autor. En este documento, se expone información importante sobre los saberes y las prácticas en salud tradicional de los kichwas. Empero, más que un esfuerzo de divulgación de los detalles de la medicina tradicional kichwa, el documento presenta una historia escrita de la migración y el asentamiento de los kichwas en el país que adquiere un carácter de "historia oficial" o "versión oficial". Este es el primer registro escrito de una memoria de la migración y el asentamiento de los kichwas en Colombia; de ahí su importancia analítica y política. En esta historia sobresalen algunas representaciones y modelos de indígenas kichwas que son 


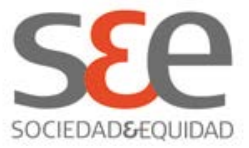

promovidos, legitimados e institucionalizados gracias a la acción del cabildo kichwa.

La historia en mención se construye a partir de narrativas de familias originarias que se representan como "próceres" y "pioneras" del proceso de migración y asentamiento de los kichwas en Colombia. En tales narrativas se exaltan cualidades como el carácter migrante del pueblo kichwa, las habilidades en el comercio, el prestigio, la solidaridad y el compañerismo entre kichwas a través de la música y el deporte. Estas cualidades se ubican en el espacio urbano de Bogotá donde adquieren significados especiales. Paralelamente, los elementos mencionados se muestran como inherentes y propios de la identidad cultural kichwa. En este escenario, subyace una tensión entre la identidad cultural kichwa que permanece y se reproduce en el tiempo, y la que se ha transformado para incorporar el cambio y la movilidad. Esto implica, por un lado, la creación de una identidad kichwa esencializada, y por otro lado, la reinvención de la misma en contextos de transformación dramática.

En los años cuarenta tuvo lugar un proceso de migración creciente de kichwas a Colombia cuya motivación fue su voluntad de establecer intercambios comerciales. Dichos intercambios se situaron en unas dinámicas comerciales y económicas específicas que caracterizaron la frontera colomboecuatoriana de esa época. Los realizadores de la historia ${ }^{2}$, lo retratan de la siguiente forma:

Por el espíritu ancestral que tiene la nación kichwa identificamos que los primeros kichwas que Ilegaron a Bogotá, lo hicieron con la intención de generar intercambios culturales e ingresos complementarios a través del comercio, de artesanías, pero conservando su identidad cultural y su lugar de asentamiento en el territorio de origen (Comunidad Kichwa, 2007: 27).

Primeramente, los historiadores resaltan cómo la llegada de los kichwas a Colombia no transformó su identidad cultural. Más bien, se puede decir que a

\footnotetext{
2 Por "realizadores de la historia" me referiré a aquellos líderes políticos del cabildo y al equipo de investigación que reconstruyó y escribió la historia de la migración y el asentamiento del pueblo kichwa. Esto obedece a mi deseo de no presentar visiones únicas, homogéneas y hegemónicas de las narrativas de la migración y el asentamiento de los kichwas en Colombia. En ese punto, tendré en cuenta que la historia en mención refleja las posturas, deseos y acciones de los realizadores de la historia en la construcción de la misma.
} 


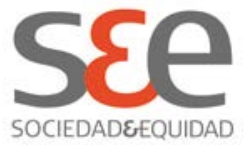

pesar de la migración, la identidad cultural kichwa se preservó a través del vínculo todavía existente con el territorio de origen, es decir, Otavalo. En ese momento surge una primera permanencia de la identidad cultural kichwa en territorio colombiano, la cual es posible en parte gracias a la aparición de familias originarias, próceres y pioneras de esta llegada. Esta permanencia se relaciona con la práctica de la migración y la asunción de Otavalo como un referente cultural compartido por la colectividad. Esto se ejemplifica de la siguiente manera:

En las entrevistas (a los líderes de la comunidad kichwa ${ }^{3}$ ) se refiere a la llegada de primeros kichwas en la década de 1940. Se habla de Antonio Quinche (Soldado) y su esposa Mercedes Lema, Segundo Quinche Maldonado (Chimbalo), Rafael Tuntaquimba Cotacachi (Lluchu Mediano) y Antonio Lema, como los pioneros y próceres de este proceso de migración motivado por el espíritu emprendedor y la habilidad innata para el desarrollo de actividades comerciales del pueblo kichwa, que ha motivado desde tiempos ancestrales la realización de múltiples viajes, que se convierte en un eje para el fortalecimiento cultural, pero sin perder de referencia las directrices de la cosmovisión kichwa (...) El pueblo kichwa desde épocas prehispánicas y dadas sus excelsas habilidades para el comercio y la producción textil que los identifica, se ha caracterizado por ser un pueblo migrante y con fuertes tendencias a habitar en contextos urbanos, lo que no ha sido obstáculo para que mantenga profundas raíces de pertenencia a su territorio de origen (Comunidad Kichwa, 2007: 28).

El exaltar las habilidades de los kichwas en el comercio, su espíritu viajero, el vínculo con Otavalo y el "no perder de referencia las directrices de la cosmovisión kichwa" mientras se "habita en contextos urbanos", refleja las posiciones de enunciación de los historiadores y su rol en la construcción de un modelo de identidad cultural kichwa terminado, así como de las acciones que están en juego para legitimarlo a través de la acción del cabildo. Por medio de esta institución de gobierno indígena, se crea una historia en común, una cultura compartida y un pasado ancestral que es reconocido públicamente por

\footnotetext{
${ }^{3}$ Luis Albancando, Luis Enrique Tuntaquimba y Segundo Quinche, en entrevista en el año 2007 para la construcción de la "Cartilla de Fortalecimiento de la Medicina Tradicional de la Comunidad Indígena Kichwa de Bogotá".
} 


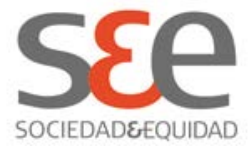

la colectividad kichwa en la ciudad. Esto es posible a través del poder simbólico que esta historia oficial tiene en la construcción cultural, social y política de dicha colectividad.

Lo anterior puede ser visto a través de las conceptualizaciones de Stuart Hall (2010) y Peter Wade (2002) sobre la identidad cultural. Hall (2010) afirma que las prácticas de representación se configuran a partir de posiciones de enunciación desde las cuales se habla o se escribe. Desde dichas prácticas, Hall (2010) plantea dos formas de definir la identidad cultural. En primer lugar, la identidad cultural se conceptualiza en términos de una cultura compartida, como "una especie de verdadero sí mismo oculto dentro de otros sí mismos más superficiales y artificialmente impuestos" y que posee un pueblo con una historia y una ancestralidad compartida (Hall, 2010: 349). En segundo lugar, la identidad cultural se concibe como un punto de confluencia de similitudes donde se expresan puntos críticos de diferencia profunda y significativa en torno a "eso que somos realmente, (y) lo que nos hemos convertido pues la historia ha interferido en nosotros" (Hall, 2010: 39-351). Con relación a esto, Wade (2010) indica que la identidad cultural está definida en medio de relaciones de poder. Por esta razón, los posicionamientos juegan un papel fundamental en la definición de una identidad cultural.

En los años cincuenta, los kichwas establecieron sus primeros asentamientos fijos de familias que se dedicaron al comercio artesanal y textil como principal actividad económica. En este punto, los realizadores de la historia relatan hechos alusivos a los reconocimientos y premios que recibieron las familias próceres y pioneras a causa de su habilidad y su éxito, lo cual se puede leer en claves de "prestigio":

Varios de los pioneros y próceres del pueblo kichwa en Bogotá, fueron Rafael Tuntaquimba Cotacachi y Rosa Elena Quinche Maldonado, quienes se dedicaron por sus habilidades en la manufactura y comercio de textiles alcanzando un reconocimiento nacional e internacional. Es así, como desde su llegada en 1945 se caracterizan por la excelsa manufactura de casimires (o paños ingleses), que lograron posicionarse por su calidad en varios países (...) En 1951, Rafael Tuntaquimba recibe un premio como mejor muestra de paño inglés en el Ecuador con el auspicio de la Casa de la Cultura de Quito (Comunidad Kichwa, 2008: 29). 


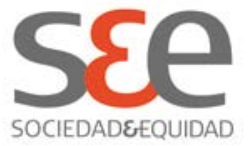

Acto seguido, los realizadores de la historia relataron cómo Rafael Tuntaquimba y Segundo Quinche recibieron premios y reconocimientos por dirigentes políticos como el Presidente conservador Laureano Gómez y la lideresa María Eugenia Díaz, de quien recibieron condecoraciones como huéspedes ilustres del palacio San Carlos. Así, la habilidad en el comercio se constituye en un referente de reconocimiento y reputación para los kichwas. El reconocimiento, la reputación, los premios y las condecoraciones son llevados al plano de la construcción de la identidad cultural del pueblo kichwa. Es en este lugar donde el prestigio toma gran relevancia.

Durante los años sesentas, las familias originarias emprendieron viajes por Latinoamérica con el objetivo de mostrar, vender e intercambiar mercancías. Al mismo tiempo, otras familias de kichwas llegaron al país no sólo con propósitos comerciales, sino también culturales. Fue así como algunas de estas Ilegaron a Bogotá como producto de giras musicales. En el plano de la música, los realizadores de la historia ubican la solidaridad entre kichwas como algo inmanente a la construcción histórica de su identidad cultural, lo cual trae consigo un esfuerzo de dignificación de estos como pueblo indígena. Simultáneamente, esto se representa a través de los próceres y los pioneros en mención. Esto puede ser visto del siguiente modo:

En la década de 1960, podemos ubicar a estos personajes históricos como un símbolo de la expansión y asentamiento del indígena kichwa en varias partes del mundo, así como de cualidades que empiezan a caracterizar nuestro pueblo: habilidad en los textiles, solidaridad entre compañeros indígenas que Ilegaban a la ciudad en busca de trabajo o como parte de giras musicales. Es el caso de los grupos Indoamérica Pukara y Ñanda Mañasi, todos del Ecuador y Aymaras de Bolivia, quienes se alojaron en la casa de Rafael Tuntaquimba y Rosa Elena Quinche, a comienzos de la década de los setentas. Entre las personas que se establecieron en Bogotá, en los comienzos de los setentas, podemos nombrar a J osé Manuel Amaguaña (Patauco), Matilde Lema, Rafael Lema (Bocachica), Mercedes Quinche, Antonio Terán (Redondilla) y su esposa Carmen; Antonio Farinango (El Turco), Tarquino y Enrique Albancando y Joaquín, Segundo Yamberlá y Juan Cuschcagua (Comunidad Kichwa, 2007: 29-30). 


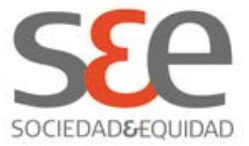

En la misma época, la colonia kichwa de Bogotá organizó eventos deportivos para promover la integración entre sus miembros. De este modo, fueron realizadas diversas actividades deportivas en el campus de la Universidad Nacional de Colombia y de la Universidad de la Salle, el Parque El Salitre, el Parque El Luján, y las canchas del barrio urbano Boyacá Real. En el ámbito de la práctica deportiva, los realizadores de la historia exaltan la solidaridad y el compañerismo entre kichwas:

Aunque las actividades culturales, musicales y comerciales caracterizan a la población indígena kichwa de Bogotá, también están presentes las prácticas deportivas a través de las cuales se fortalece la apropiación de lugares específicos dentro de la ciudad y además permite el intercambio de amistad y compañerismo (Comunidad Kichwa, 2007: 30).

Entonces, la práctica deportiva no sólo se presentó como un espacio de intercambio entre kichwas ecuatorianos y colombianos, sino como un territorio donde se recrea una identidad y un referente cultural compartido. En este contexto, los kichwas de ambos países se convierten en un solo pueblo más allá de las fronteras. Adicionalmente, la lógica de representar simbólicamente pioneros, próceres y personajes históricos como facilitadores de los procesos de construcción identitaria, siguen siendo preponderantes en la narración de la solidaridad entre kichwas en el ámbito del deporte.

Para los realizadores de la historia, la década de los ochenta trajo consigo la consolidación de redes de fortalecimiento y solidaridad entre kichwas, el crecimiento de la migración y la población en Bogotá, y el auge de la música y el comercio. En este punto, la música no sólo es entendida como un espacio de intercambios, solidaridades y compañerismos, sino también como un terreno de reivindicaciones políticas. En ese periodo de tiempo, se tejió un puente de diálogo y retroalimentación mutua entre los saberes musicales y las luchas políticas. Esto se materializó en la voluntad de algunos líderes kichwas de organizar políticamente a la comunidad:

Debido a estos fenómenos culturales, sociales, y económicos que se manifiestan en la ciudad de Bogotá y buscando la unificación y el fortalecimiento cultural del pueblo kichwa, sobresalen algunos líderes e instituciones culturales como es el caso del grupo Kapary Walk'a que propenden por la defensa y reclamo de los derechos humanos fundamentales. A través de este encuentro entre los líderes José Villagrán (radicado en Saravena, Arauca), y Luis Enrique Tuntaquimba 


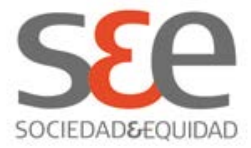

acompañados del grupo Kapary Walk'a, surge la inquietud de una conformación del Cabildo Mayor Kichwa de Bogotá en junio del año 2001. Atendiendo a esta necesidad y al Ilamado histórico de la nación kichwa, se inicia el proceso del cabildo en cabeza de algunos miembros de la comunidad interesados en este proyecto como son: Esteban Amaguaña, José Villagrán, Luis Enrique Tuntaquimba, Luis Enrique Albancando, Antonio Terán, Enrique Morales (el Santos), Agustín Amaguaña, Luis Alfonso y Nelson Tuntaquimba, como también William Albancando, Enrique Cepeda, José Luis Santillán, entre otros (Comunidad Kichwa, 2007: 32).

El cabildo fue conformado a partir de deliberaciones y encuentros realizados periódicamente con la comunidad kichwa de Bogotá, liderados por las personas anteriormente mencionadas. Inicialmente, los puntos de reunión durante los años que antecedieron a la constitución del cabildo en el año 2006, fueron la Plaza España o San Victorino en el centro de Bogotá. Estos lugares son concebidos como simbólicos para los kichwas puesto que fue allí donde se establecieron los primeros intercambios comerciales y culturales entre los miembros de la colonia.

Conformado el cabildo como institución de gobierno indígena, los líderes generaron iniciativas para institucionalizar las prácticas culturales otavaleñas en el contexto de Bogotá. De este modo, el cabildo empezó a organizar anualmente la celebración del Inti Raymi. Para esto, el cabildo prepara el evento e invita a los kichwas que residen tanto en Bogotá como en toda Colombia. Además, a esta fiesta llegan kichwas provenientes de Ecuador, Perú, Bolivia, entre otros, así como otros pueblos indígenas tales como los ingas y los ambiká-pijaos.

Gracias a la acción del cabildo, se institucionaliza una imagen modelo de los kichwas que viven en Colombia, delimitándose así como un grupo étnico con unas prácticas y una identidad específica. De este modo, la identidad de los kichwas se esencializa con el fin de garantizar su reproducción a través del gobierno indígena. Esta representación del kichwa modelo se puede identificar a continuación:

Bogotá cuenta con 1250 indígenas del pueblo kichwa otavaleño, oriundos específicamente de la Provincia de Imbabura, quienes se encuentran organizados políticamente en un cabildo indígena de acuerdo al marco legal nacional y distrital, reconocido desde 2006, sin embargo, habitan 


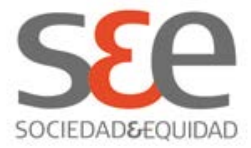

en la sabana de Bogotá aproximadamente desde 1920. Esta población, que se encuentra dispersa geográficamente en varias localidades del Distrito Capital, entre ellas, Engativá, Puente Aranda, Kennedy, Suba, Mártires, Santa Fe, Chapinero, Fontibón y Candelaria, provienen como pueblo milenario del vecino país del Ecuador, descendientes de los shiry-incas. Como pueblo migrante, la gran mayoría de sus miembros ostentan una nacionalidad de indígenas colombo-ecuatorianos, quienes se desenvuelven en actividades económicas y culturales tales como el tejido tradicional con telar manual, artesanías, música y danza, con elementos identitarios que los diferencian del resto de la población, así como la lengua kichwa o Runa Shimi, así como celebraciones rituales como el Inti Raymi (...) la población kichwa que habita en Bogotá, mantiene lazos estrechos con sus comunidades de origen. Cabe decir que el pueblo kichwa ha logrado construir dispositivos culturales para generar fronteras frente a la población que los acoge, al mishu (Comunidad Kichwa 2007, 22 y 33).

De esta imagen modelo de los kichwas en Colombia, sobresalen algunos puntos que comparten con los kichwas otavaleños en lo que atañe a la construcción identitaria. En primer lugar, se resalta el pasado inca de los otavalos como un referente histórico y comúnmente compartido. En segundo lugar, predomina el carácter migrante y el desenvolvimiento en actividades comerciales como elemento constitutivo de la identidad cultural. En tercer lugar, se establecen la lengua y la celebración del Inti Raymi como un distintivo de lo kichwa hacia lo mishu, es decir, hacia lo mestizo y, en este medida, hacia el "otro". Esto último delimita las diferencias entre la cultura kichwa y otras culturas que perviven en el medio urbano en el cual interactúan. En este sentido, la cultura kichwa se constituye en un elemento único e impenetrable por otras culturas. Esto es paradójico teniendo en cuenta que la indigeneidad kichwa ha estado marcada por el cambio y la contingencia.

Finalmente, en la historia oficial de la migración y el asentamiento de los kichwas en Colombia es posible rastrear las permanencias que emergen de la relación conflictiva entre una identidad cultural kichwa esencializada, y una que se define a la luz del cambio y la movilidad en un contexto de transculturalidad. Esto se refleja en la imagen simbólica del kichwa modelo que reproduce el cabildo a través de las narrativas de próceres y pioneros que se representan en dicha historia. Esta relación conflictiva entre estas formas de 


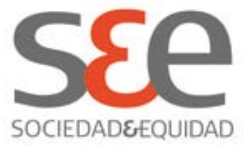

identidad cultural kichwa, es igualmente reproducida a través de la acción del cabildo indígena. Esta acción tiene como fin explícito el garantizar la permanencia de la colectividad kichwa en Bogotá a través del tiempo.

\section{Conclusiones}

Los kichwas u otavalos son un pueblo indígena ligado histórica y culturalmente a la ciudad de Otavalo en el Ecuador. Dicho pueblo adopta las prácticas de la migración, el comercio y la interpretación musical como parte de su vida cotidiana, y también, como parte de su identidad cultural. Así, desde la práctica de la migración transnacional, los kichwas pueden definirse como indígenas contemporáneos que afrontan el cambio cultural poniendo en marcha estrategias de movilidad entre culturas. Desde 1940, algunos kichwas migraron hacia Colombia con el fin de establecer intercambios comerciales. Transcurridas algunas décadas, el pueblo kichwa se conformó como colonia en los años ochentas y más tarde se organizó políticamente en torno a la figura del cabildo indígena en el año 2006.

Para este periodo de tiempo, algunos líderes de dicho cabildo crearon y fundaron una historia oficial del pueblo kichwa donde la migración y el comercio, sumadas a cualidades como la habilidad en la fabricación de textiles, el prestigio, la solidaridad y el compañerismo, se legitimaron como elementos simbólicos de la identidad cultural de los kichwas en Bogotá. Esto es posible gracias a la representación de narrativas de próceres y pioneros de la migración y el asentamiento de este pueblo indígena en la ciudad. Como resultado, en esta historia oficial se refleja la voluntad de los líderes en mención: garantizar la permanencia de la cultura kichwa en el tiempo. Entonces, la historia oficial cumple un papel fundamental en los procesos de socialización de la colectividad, y en la reproducción de los saberes y conocimientos kichwas de generación en generación.

Los creadores de la historia oficial del asentamiento y la migración de los kichwas en Colombia, no sólo posicionan las narrativas de los próceres y los pioneros de estos procesos, sino que también crean modelos de indígenas kichwas que tienen como fin reproducir la cultura kichwa y su continuidad en el tiempo. Los elementos que caracterizan este modelo de kichwas son, a saber: 1) el carácter migrante de los indígenas kichwas y su desenvolvimiento en actividades comerciales; 2) la adopción de la lengua y el vestido inca; 3) la celebración de fiestas tradicionales como el Inti Raymi, y 4) la interacción constante con el entorno urbano bogotano, uno en torno al cual crean su identidad indígena y se diferencian de los otros, es decir, los mestizos. Esto último conduce al establecimiento de diferencias culturales entre el pueblo kichwa y otros grupos humanos con los cuales comparten el mismo espacio urbano. 


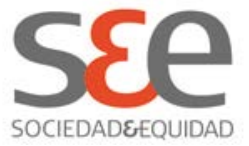

La interpretación cultural de la historia de la migración y el asentamiento del pueblo kichwa en Colombia retomó la crítica a la representación y la autoridad de la antropología, así como algunos aportes de la disciplina a la investigación sobre indigeneidades. Teniendo en mente dichos aportes, se expusieron algunas consideraciones que guiarían dicha interpretación. En primer lugar, se asumió que tanto en el acto de interpretar como en la creación de esta historia sobresalen dos tipos de autoridad. Una, se sustenta en la voluntad de visibilizar las voces y posiciones particulares de los realizadores de la historia. La otra, se relaciona con las posiciones de enunciación de dichos realizadores. En segundo lugar, se admitió que la historia de la migración y el asentamiento del pueblo kichwa, refleja los valores, prácticas, identidades y sujetos que definen su cultura. Finalmente, se consideró que la historia oficial está imbricada en relaciones de poder cuyas consecuencias políticas y sociales son imposibles de mitigar. Por lo tanto, en aras del cometido ético de no dañar a los kichwas con esta interpretación, se habló más del fin que cumplía la historia oficial en los procesos de socialización de la comunidad, más que de una instrumentalización de la identidad kichwa con fines políticos.

\section{Referencias Bibliográficas}

Comunidad Indígena Kichwa de Bogotá. (2007). Cartilla de fortalecimiento de la medicina tradicional de la comunidad indígena kichwa de Bogotá. Bogotá.

Colloredo-Mansfeld, R. (1998). "Dirty Indians", Radical Indigenas, and the Political Economy of Social Difference in Modern Ecuador. Bulletin of Latin American Research, 17(2), 185-205.

Colloredo-Mansfeld, R. (2002). "Don't be lazy, don't lie, don't steal": Community Justice in the Neoliberal Andes. American Ethnologist, 29(3), 637662.

Hall, S. (2010). Identidad cultural y diáspora. En Sin garantías. Trayectorias y problemáticas en estudios culturales (pp. 349-462). Popayán-Lima-Quito: Envión Editores-IEP- Instituto Pensar-Universidad Andina Simón Bolívar.

Jackson, J., \& Warren, K. (2005). Indigenous Movements in Latin America, 1992-2004: Controversies, Ironies, New Directions. Annual Review of Anthropology, 34, 549-573.

Korovkin, T. (1998). Commodity Production and Ethnic Culture: Otavalo, Northern Ecuador. Economic Development and Cultural Change, 47(1), 125-154.

Kovach, M. (2012). Indigenous Methodologies. Characteristics, Conversations, and Contexts. Toronto: University of Toronto Press. 


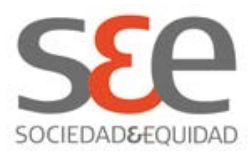

Maldonado, G. (2002). Pasado y presente de los mindalaes y emigrantes otavalos. Íconos. Revista de Ciencias Sociales, (014), 46-55.

Meisch, L. (2002). Andean Entrepeneurs. Otavalo Merchants \& Musicians in the Global Arena. Austin: University of Texas Press.

Tuhiwai-Smith, L. (2012). Decolonizing Methodologies. Research and Indigenous Peoples. Londres- Nueva York: Zed Books.

Wade, P. (2002). Identidad. In Palabras para desarmar (pp. 255-264). Bogotá: ICANH.

Welsch, W. (1999). Transculturality - The Puzzling Form of Cultures Today. In Spaces of Culture: City, Nation, World (pp. 194-213). Londres: Sage. Recuperado de: http://www2. unijena. de/ welsch/ Papers/ transcultSociety. html

Wibbelsman, M. (2005). Otavaleños at the Crossroads: Physical and Metaphysical Coordinates of an Indigenous World. The Journal of Latin American Anthropology, 10(1), 151-185. 